\title{
Positive and Negative Effects of Republicanism on US citizens' Mobility During the First Period of the COVID Crisis
}

Guillaume Barbalat ( $\sim$ guillaumebarbalat@gmail.com )

Cornell University

Nicolas Franck

Claude Bernard University Lyon 1

\section{Research Article}

Keywords: Republicanism, political partisanship, COVID-19, Mobility, Anti-COVID interventions, Risk perception

Posted Date: October 21st, 2021

DOl: https://doi.org/10.21203/rs.3.rs-955556/v1

License: (c) (i) This work is licensed under a Creative Commons Attribution 4.0 International License.

Read Full License 


\section{TITLE PAGE}

Positive and negative effects of republicanism on US citizens' mobility during the first period of the COVID crisis

Dr Guillaume Barbalat ${ }^{1-2}$, MD PhD \& Pr Nicolas Franck ${ }^{2}, M D$ PhD

\section{Authors affiliations}

${ }^{1}$ Department of Population Health Sciences

Weill Cornell Medicine

1300 York Ave,

NY 10065

USA

${ }^{2}$ Centre Ressources de Réhabilitation Psychosociale et de Remédiation Cognitive CH Le Vinatier \& Université Claude Bernard Lyon 1

France

Corresponding author:

Guillaume Barbalat

Department of Population Health Sciences

Weill Cornell Medicine

1300 York Ave,

NY 10065

USA

guillaumebarbalat@gmail.com 
ABSTRACT

While Republican states have been criticized for their limited efforts to contain the spread of COVID-19, it is important to consider that political orientation can modify human behaviour via complex effects that are still poorly understood. During the first period of the pandemic, we found that the association of republicanism with US citizens' mobility varied depending on the nature of the exposure being considered. First, republicanism was associated with increased mobility when the stringency of anti-COVID measures increased. Second, republicanism was associated with decreased mobility when COVID-related deaths increased. Third, republicanism was associated with increased mobility over time, i.e. as time went by, citizens living in Republican states were more mobile than those in Democratic states. These findings raise caution on any over-interpretation of the impact of polarization in US politics on COVID-related behaviour. They prompt consideration of persuasive tools that emphasize risk perception to promote social distancing in Republican states, rather than relying heavily on stringent anti-COVID interventions.

\section{KEYWORDS}

Republicanism, political partisanship, COVID-19, Mobility, Anti-COVID interventions, Risk perception 


\section{MAIN TEXT}

\section{Introduction}

Republican states have been blamed for their relative leniency towards limiting the spread of SARS-COV-2 ${ }^{1,2}$. This is especially true when considering efforts to increase social distancing and to restrict people's mobility to places where the virus is mostly transmitted, e.g. transit stations, businesses, schools and universities ${ }^{3-8}$. In turn, these were thought to result in a higher overall prevalence of COVID cases and deaths in Republican than Democratic states ${ }^{8-11}$.

These differences in COVID-related infection and death rates have been accounted for by the lower strength of anti-COVID interventions observed overall in Republican states ${ }^{9}$. Yet, differences in political affiliation may also translate into differences in human mobility via more subtle, indirect effects. First, others have shown that citizens from Republican states were less compliant with stay-at-home orders compared with their Democratic counterparts 8,12. This suggests that, even at similar levels of interventions, those with a Republican orientation would tend to be more lenient towards respecting anti-COVID measures. Second, changes in social distancing may also reflect individuals' beliefs about disease risk, irrespective of government policies ${ }^{13-16}$. In other words, those who are more afraid of "catching the virus" would be more tempted to adopt self-protective behaviours (stay home rather than go out). Political orientation can greatly modify risk assessment, in particular citizens' beliefs or level of concern about the virus ${ }^{17}$, which could have great consequences on their behaviour (including mobility) during the pandemic. Third, holding constant the strength of anti-COVID interventions and risk perception, citizens' mobility could also vary as a function of time, for instance be attenuated or amplified as a result of varying intensity of enforcement, interventions on social media, nudging, or habituation, boredom and anger effects ${ }^{18,19}$. For instance, over time citizens have received various messages from political 
parties, accurate or not, about the need to distance and the severity of the disease ${ }^{20,21}$, and more recently about vaccination risks and effectiveness.

Little is known about these moderating effects of political orientation on citizens' behaviour in response to the COVID crisis. Their investigation would however be of paramount importance to better understand the natural tendencies and fine-grained mechanisms underlying the influence of political affiliation on people's behaviour, and further, how to counteract them when they result in significant health and social burden. In the current study, we sought to determine how republicanism affected US citizens' behaviour during the first period of the pandemic, via its effect on citizens' compliance with anti-COVID measures, on their perception of COVID-related risks, as well as over time. We chose mobility to transit stations as our outcome variable since that measure would theoretically be closely linked to a higher spread of the virus ${ }^{22}$. As proposed by others, we used the local cumulative number of COVID deaths and cases as proxies for informational inputs about general perception of COVID risks during the pandemic ${ }^{19}$. Finally, we chose to circumscribe our analysis to the beginning of the pandemic (from Mid-February to end of May 2020) as we did not want the US presidential elections campaign to amplify the bias inherent to political polarization on citizens' behavioural response. 


\section{Methods}

\section{Data}

\section{Outcome variable (Mobility to transit stations)}

We used the Google COVID-19 Community Mobility Reports database to extract state-wise daily percentage change in mobility to transit stations ${ }^{23}$. This database has been used extensively to assess various interventions during the pandemic. It provides time series cross sectional daily data for six particular categories of mobility data: (1) transit stations; (2) retail and recreation places; (3) workplaces; (4) groceries and pharmacies; (5) residential places; (6) parks. Observations are based on cellular phone, laptop and tablet signals. Specifically, the data shows how visits and time spent in the above places change compared to so-called "baseline days". For each day of the week, the baseline day is the median value from the 5-week period Jan 3 - Feb 62020 (i.e. before the pandemic hit the US, hence before restrictions on movement) for a specific location and a specific mobility category. For each day, an integer value gives the percent change in mobility (positive or negative) compared to that same day during that 5-week period (Jan 3 - Feb 6).

In the current study, we chose mobility to transit stations as our main outcome of interest and used other measures in our sensitivity analysis ${ }^{24}$. We chose to restrict our time series to the period from February the 15th 2020 (start date of the database) till May the 31th 2020. The latter is often taken as the end of the first wave of the pandemic. In total, our time series amounts to 107 days. Overall, our data comprised $N=51$ states $\times 107$ days $=5457$ observations. There were no missing values.

\section{Political orientation}

Each state's political orientation was defined as each state trifecta as of 2020 (Democratic vs. divided vs. Republican) and retrieved from the ballotpedia website ${ }^{25}$. In the 
Supplementary Materials 1, we provide a list of US states according to their political affiliation.

\section{Stringency of anti-COVID measures}

For each state and each day, a measure of the stringency of anti-COVID interventions was extracted from the Oxford COVID-19 Government Response Tracker (OxCGRT) ${ }^{26}$. In short, the OxCGRT provides a measure of stringency on a scale from 0 to 100 , publicly available on GitHub ${ }^{27}$. This measure is based on a summary of seven indicators on policies regarding social isolation and confinement, including school, workplace, and public transport closures, public events cancellations, stay at home requirements, and restrictions on gatherings and internal movement. Data is collected from publicly available sources such as news articles and government press releases and briefings. Each indicator measures the stringency of each policy or intervention on an ordinal scale of severity or intensity (from no measures taken to simple recommendations and implementation of the policy). Note that OxCGRT measures for US states do not include federal policies that apply to the country as a whole (e.g., international travel bans).

We reasoned that the effect of anti-COVID measures would be expected on citizens' mobility on the day they were introduced, as in ${ }^{28}$, therefore we did not include any lags in the "Stringency" time series.

\section{Cumulative number of COVID deaths}

We used the daily cumulative number of COVID deaths in each state as a reflection of the amount of risks due to COVID perceived daily by citizens in each state ${ }^{19}$. Indeed, we reasoned that a great marginal increase in the number of COVID-related deaths would inform citizens that the current status of the pandemic may be dangerous. And in turn, a large (negative) effect of the number of COVID deaths on mobility would suggest that citizens take great precautions against the virus by not going out. For each state and each day, the cumulative number of confirmed COVID-related deaths was extracted from the 
Oxford COVID-19 Government Response Tracker, and lagged by one day ${ }^{27}$. Note that for the purpose of our research question, we indeed reasoned that an optimal way to model the impact of COVID deaths on citizens' mobility would be to use the raw number of deaths rather than rates. This is because our hypothesis relies on the impact of COVID deaths on mobility via people's perceptions of the danger to go out due to an increased number of COVID deaths. In that sense, we hypothesized that a raw number would be more meaningful to people than a (relatively small) rate.

\section{Temperature}

We included a climate variable in our statistical model as we reasoned that climate might confound the relationship between COVID deaths and mobility. We retrieved the mean temperature (in degrees Fahrenheit) of each state's capital city for each day of our time series from the wunderground website ${ }^{29}$.

\section{Analysis}

\subsection{Main analysis}

We specified multivariate linear models using directed acyclic graphs to include variables that appeared to determine mobility to transit stations (Supplementary Materials 2). Specifically, we fit our time series of the mobility to transit stations according to the following linear equation:

$$
\begin{aligned}
\text { Mobility }_{s d} & =\beta_{0}+\beta_{1} \text { Stringency }_{s d}+\beta_{2} \text { Stringency }_{\text {sd }} * \text { Republicanism }_{s} \\
& +\beta_{3} \text { Death }_{s d}+\beta_{4} \text { Deaths }_{s d} * \text { Republicanism }_{s} \\
& +\beta_{5} \text { Temp }_{s d}+\beta_{6} \text { Temp }_{\text {sd }}^{2} \\
& +\beta_{7} \text { Trend }_{d} * \text { Republicanism }_{s} \\
& +\theta_{s}+\delta_{d}+\epsilon_{s d}
\end{aligned}
$$


, where:

- Mobility $_{s d}$ is the percent signal change from baseline in mobility to transit station, for state $s$ at day $d$;

- Stringency ${ }_{s d}$ is a measure of the stringency of anti-COVID interventions, for state $s$ at day $d$;

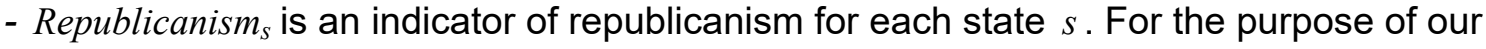
main analysis, we define a crude index of republicanism according to each state's trifecta, where Democratic states would be affiliated the value of 0 , divided states the value of 1 , and Republican states the value of 2 ;

- Deaths $s_{s d}$ is the number of COVID deaths (cumulative) for state $s$ at day $d$;

- $T e m p_{s d}$ and $T e m p^{2}{ }_{s d}$ are measures of the mean temperature of each state $s$ capital city at day $d$ (raw and squared terms, respectively);

- Trend $_{d}$ indicates temporal count, taking the value $d$ at day $d$. Note that we also tested a model including a non-linear, quadratic temporal trend, which we subsequently decided to remove as it was non-significant;

- $\beta_{i}$ indicates the parameter estimate of the respective regressor $i$. We were specifically interested in $\beta_{2}$ and $\beta_{4}$, which represent the effect of anti-COVID stringency measures and cumulative COVID Deaths on citizens' mobility moderated by republicanism, respectively. We were also interested in $\beta_{7}$, which represents the effect of republicanism on mobility over time;

- $\theta_{s}$ represent states fixed effects for each state $s$. States fixed effects are "omitted" and unobserved state-level time-invariant factors that distinguish US states and that could bias our statistical estimates of interest. These would be confounders in the relationship between treatments and outcome, i.e. factors that may influence anti-COVID measures and/or the cumulative number of COVID deaths, as well as citizens' mobility. Such factors might be (but are not restricted to): population-level risk preferences ${ }^{30}$, general level of trust to politicians 
and healthcare systems ${ }^{31}$, culture, ethnicity and religion, population density, percentage of urban population, share of population aged 65 or older, average household size,

unemployment rate, income per capita and income inequality ${ }^{32-34}$, percentage of the population with risk factors for COVID-19 (such as obesity or cardio-vascular disease), state's physician rate;

- $\delta_{d}$ represent days fixed effect for each day $d$. Days fixed effects model time-varying state-invariant factors that may confound our main relationships of interest. In short, these would be represented by nationwide daily variability in movement, for instance due to national holidays, weekend days, vacation periods, economic downturns, or nationwide weather patterns;

- $\epsilon_{s d}$ is the model residual for state $s$ at day $d$.

Because policy stringency and the number of COVID deaths likely correlate with the time variable, the presence of multicollinearity among variables included in the model was investigated. The variance inflation factor was below 7.5 for each regressor, and below 5 for our three regressors of interest. When we further scaled the temperature variable (linear and quadratic terms), the variance inflation factor was below 5 for each regressor, without any change in the mean coefficient value for each parameter of interest $\left(\beta_{2}, \beta_{4}\right.$ and $\left.\beta_{7}\right)$.

Cluster robust standard errors were estimated to account for the correlation of data within each state. Note that we did not include a main effect of republicanism, nor a single linear temporal trend in our statistical model as these would be collinear with states and days fixed effects, respectively.

\subsection{Event-studies}

We performed additional analysis where variables Stringency, Deaths and Trend were binearized. Specifically, Stringency, Deaths and Trend were discretized into 10 categorical 
bins, such that each bin contained enough data to perform additional regression analyses (see Supplementary Materials 3 for a table summarizing the number of observations contained in each bin for each political group). Doing so, the chances of data sparsity were reduced, which improves the interpretability of our results. Another reason why we performed these additional analyses is that they provide better insights on the effect modification of Stringency, Deaths and Trend by republicanism, because binearization allows better visualization of subtle non-linear effects.

We specified the following linear equation:

$$
\begin{aligned}
\text { Mobility }_{s d} & =\beta_{0}+\beta_{1} \text { Stringency }_{s d}+\sum_{i=1}^{10} \alpha_{i}\left(\text { BinStringency }_{\text {sdi }} * \text { Republicanism }_{s}\right) \\
& +\beta_{3} \text { Deaths }_{s d}+\sum_{j=1}^{10} \gamma_{j}\left(\text { BinDeaths }_{s d j} * \text { Republicanism }_{s}\right) \\
& +\beta_{5} \text { Temp }_{s d}+\beta_{6} \text { Temp }_{s d}^{2} \\
& +\sum_{k=1}^{10} \lambda_{k}\left(\text { BinTrend }_{s d k} * \text { Republicanism }_{s}\right) \\
& +\theta_{s}+\delta_{d}+\epsilon_{s d}
\end{aligned}
$$

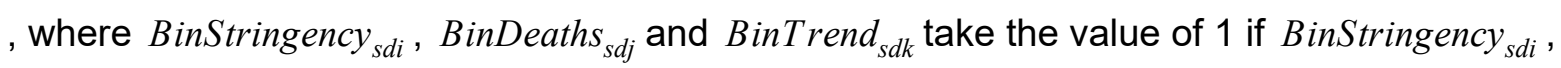
BinDeaths $_{s d j}$ and BinTrend Bdk $_{\text {B }}$ correspond to the value of $i, j, k$, respectively.

$\alpha_{1}, \gamma_{1}, \lambda_{1}$ are the reference coefficients and are set to 0 .

$\alpha_{i}, \gamma_{j}, \lambda_{k}$ therefore indicates the effects of republicanism on mobility at each bin $i, j, k$ comparatively to that at bins $i=1, j=1$, and $k=1$ for Stringency, Deaths and Trend, respectively.

We then reported so-called "event-study plots" to illustrate the effect of each binearized variable, modified by republicanism, on the outcome. 


\subsection{Sensitivity analysis}

We ran the following sensitivity analysis to check that subtle changes in measurement would not invalidate our conclusions.

\section{Outcome variable.}

Here, we substituted mobility to transit stations to that of other places where signals were recorded in the Google COVID-19 Community Mobility Reports database: retail and recreation places, workplaces, groceries and pharmacies, residential places, and parks.

We hypothesized that our estimates of interest would not substantially change as compared to those obtained with mobility to transit stations when outcome variables were mobility to retail and recreation places, workplaces, and groceries and pharmacies. For residential places, we hypothesized that estimates would be of an opposite sign than those obtained with transit stations. Finally, we hypothesized that estimates would be non-significant for mobility to parks, as we reasoned that these would be much less impacted by subtle exposure changes.

\section{Measurement of republicanism}

Here, we changed our strategy for measurement of republicanism. Using data from the Pew Research Center, we differentiated states in terms of their percentage of voters for the Republican candidate at the 2016 presidential elections (former President Trump), rather than a rough differentiation of their political group as we did in the main analysis (Democratic vs. divided vs. Republican states) ${ }^{35}$.

\section{Measurement of risk perception.}

We re-ran our main analysis using cumulative COVID cases instead of cumulative COVID deaths as a measure of perception of COVID risk. 


\section{Accounts of temporality}

We first tested a model taking into account a specific correlation structure of the error term, as sequences of non-seasonal Autoregressive Moving Average (ARMA) of daily values for each state, with $p=1$ lag.

Second, to test whether our results were robust to a longer period of analysis, we reproduced our event-study plots (aming to illustrate the effect of each variable of interest, modified by republicanism) over a longer period of analysis (till the end of February 2021 rather than end of May 2020).

Analyses were performed $\mathrm{R}$ version 4.0 and packages daggity, fixest and $n / m e$. 


\section{Results}

Our multivariate time series analysis aimed to linearly fit, among US states, daily mobility to transit stations (obtained from the publicly available Google COVID-19 Community Mobility Reports database) to anti-COVID stringency interventions (the so-called "Stringency" term in our statistical model), number of COVID deaths ("Deaths" term), as well as their interaction with an index of republicanism ("Republicanism" term). Republicanism was based on each state's government trifecta, and was defined as a linear increase from Democratic trifectas to divided governments and further, to Republican trifectas. We were also interested in the effect of republicanism on mobility over time ("Trend" term). Note that our model also included an index of climate (daily temperature in each state - raw and squared terms), as well as states and days fixed effects. The latter allowed to remove the variance related to state- and time-wise factors that could have had an impact on mobility to transit stations and that could have confounded the effect of party affiliation (e.g. unemployment rate, ethnicity, population density, national holidays etc...).

\section{Data description}

Figure 1 provides a plot of the mean trend for the outcome variable (mobility to transit stations) for each political group. Mobility to transit stations started to decrease after the first week of March and started to rebound after the first week of April. Overall, Republican states presented with a higher level of mobility than divided and Democratic states.

Figure 1 about here 
Figure 2 provides a plot of the mean trends for the stringency of anti-COVID interventions and the cumulative number of COVID-related deaths for each political group. Overall, Republican states underwent a lower strength of anti-COVID measures, and presented with a lower number of COVID deaths than Democratic and divided states. The latter is in line with a previous report showing that rates of COVID cases and deaths in Republican states started to exceed those in Democratic states from June 2020 onwards ${ }^{11}$.

Figure 2 about here

\section{Main results}

Table 1 provides parameter estimates for each term of our statistical model. As expected, there was a main effect of stringency of anti-COVID measures as well as number of COVID deaths on mobility to transit stations, such that more stringent anti-COVID interventions and a higher number of COVID deaths were related to a decrease in mobility to transit stations (p's<0.0073). An increase in temperature was also related to a significant increase in mobility $(p=0.0475)$, but the temperature square term did not have any significant effect $(p=0.1952)$.

Interactions between our index of republicanism with (1) stringency of anti-COVID measures, (2) number of COVID deaths and (3) linear temporal trend were all significant (p's<0.006). Specifically, the effect of stringency on mobility was moderated by republicanism, such that republicanism was associated with increased mobility at higher stringency levels (main effect of Stringency: $b=-0.2126, p=0.0027$; Stringency $x$ Republicanism interaction: $b=0.0810, p=0.006$ ). All other parameters being kept constant, an increase of 50 units on the Stringency scale was associated with a decrease of $10.5 \%$ in the percentage signal change in mobility to transit stations. Republicanism however increased 
this percentage by about $4 \%$. The effect of COVID deaths was also modified by republicanism, such that republicanism was associated with decreased mobility when the number of COVID deaths increased (main effect of Deaths: $b=-0.0003, p=0.0073$; Deaths $x$ Republicanism interaction: $b=-0.0031, p<0.0001)$. All other parameters being kept constant, an increase in the cumulative number of COVID-related deaths by 10000 was associated with a decrease of about $3 \%$ in the percentage signal change in mobility to transit stations. Republicanism further decreased this percentage by $31 \%$. Finally, republicanism was associated with increased mobility as a function of time (Trend $\mathrm{x}$ Republicanism interaction: $b=0.1076, p<0.0001)$. All other parameters being kept constant, in 10 additional days, republicanism increased the percentage signal change in mobility to transit stations by an additional $1.1 \%$.

Table about here

Figure 3 provides event-study plots for each of our three effects of interest (Stringency x Republicanism, Deaths x Republicanism, Trend x Republicanism). In general, our event-studies confirmed the significance of these three interaction terms obtained from our main analysis.

Figure 3 about here 


\section{Robustness checks}

Our sensitivity analysis revealed that our results were in general robust to changes in our outcome variable (using various measures of mobility), measurement of republicanism (using the percentage of citizens voting for the Republican candidate at the 2016 presidential elections), measurement of risk perception (using number of COVID cases rather than deaths), and accounts of temporality (taking into account the temporal correlation structure of the error term and increasing the duration of our time series) (Supplementary Materials 4).

In terms of our sensitivity analysis on outcomes, we retrieved relatively similar coefficients for Stringency $\mathrm{x}$ Republicanism, Deaths $\mathrm{x}$ Republicanism and Trend $\mathrm{x}$ Republicanism when using mobility to retail and recreation places, workplaces, or groceries and pharmacies as our dependent variable. Compared to mobility to transit stations, specifying models with mobility to residential places as our outcome demonstrated effects of an opposite sign. Finally, mobility to parks did not demonstrate any significant effect of Stringency x Republicanism, nor Deaths x Republicanism. 


\section{Discussion}

Our study provides an analysis of the association between republicanism and US citizens' mobility during the first period of the COVID-19 pandemic. Using mobility to transit stations as our dependent variable, we found that republicanism was associated with increased mobility when the stringency of anti-COVID measures increased, but decreased mobility when the number of COVID deaths increased. Over time, we observed a positive effect of republicanism on mobility: as time went by, citizens living in Republican states were more mobile than those in Democratic states. We retrieved relatively similar results when running sensitivity analysis on outcomes, modulo subtle differences that could be due to our use of a rather general measure for the strength of anti-COVID interventions.

Our study adds to the growing body of literature showing that political polarization impacts health-related behaviours, from enrollment in health care insurance to perceptions about the safety of vaccines ${ }^{7,8,12,17,36-41}$. Yet, our design also allowed us to improve our understanding of the effect of political orientation on citizens' response to the pandemic at a fine-grained level. We first showed that, in terms of mobility to transit stations, republicanism was associated with a lower compliance with anti-COVID interventions. This confirms previous findings that alignment with political ideas could bias the formation of opinions and behaviours, even when these ideas are not substantive ${ }^{39}$, and that party endorsement mitigates adherence to evidence-based policy directives ${ }^{42}$. More specifically, psychological underpinnings typically related to republicanism might be inherently unaligned with highly constraining health-related policies, even though they could benefit the whole community ${ }^{43}$. For instance, while being usually referred to as people of honor and duty, that respect authority, religion and traditions ${ }^{44,45}$, Republican citizens demonstrate significant antisocial traits ${ }^{46-48}$ and, when reflecting upon public health-related matters, show a low level of trust in their governments and healthcare providers ${ }^{19,30,31,49,50}$. Likewise, from the perspective of cultural norms, Republican citizens demonstrate less communion traits than their Democratic counterparts, and more individual, agency traits ${ }^{51}$. Overall, these psychological 
characteristics might have biased citizens from Republican states towards more reluctance to comply with constraining, "high-cost" anti-COVID measures taken by their local governments.

Second, in line with previous theories and research, we reasoned that, irrespective of government policies, learning the number of local COVID deaths would impact self-protective behaviours, because of a heightened perception of risk to catch the virus, and/or of the disease severity ${ }^{15}$. Confirming these predictions, we found an association between a greater number of COVID deaths and a decreased likelihood of going out to transit stations. Yet, we also demonstrated variations in such risk assessments across political groups, with individuals from Republican states being overall more cautious vis-a-vis the virus. Given previous research, we hypothesize that this over-cautiousness associated with republicanism might relate to: (1) a different age structure, i.e. a higher rate of older aged people who would be more risk-averse towards the virus ${ }^{52}$; (2) a specific cognitive profile, with less extraversion and risk-taking behaviours associated with republicanism ${ }^{31,32}$; and/or (3) a heightened response to fearful stimuli in Republican citizens ${ }^{53-55}$. Further research should explore how each of these factors may contribute to the perception of COVID-related risks in citizens that are differently affiliated to political parties.

Our third finding pertains to the significant difference in the temporal variation of mobility to transit stations across political groups, with an increased temporal trend in mobility associated with republicanism ${ }^{8,41}$. One potential explanation for such a temporal pattern is that the economic burden that mobility restrictions increasingly impose on individuals would be differentially appraised, and palliated for, in Republican vs. Democratic states. As an example, Republican citizens and governors demonstrated more reluctance to get federal unemployment aid ${ }^{56}$, which, in turn, could have resulted in increased mobility over time related to job hunting. A second hypothesis is that protective, yet constraining behaviours that relate to low levels of mobility may be differently integrated to social norms ${ }^{57}$ in Democratic vs. Republican states. Indeed, some have shown that Democratic citizens were in general more motivated to socially distance ${ }^{58}$, while others, more likely to be 
Republicans, would demonstrate a heightened degree of so-called "pandemic fatigue" 59-61. Thirdly, these temporal variations may have resulted from specific events, a.k.a.

discontinuities in the time series. Typically, political speeches or interventions on social media, such as statements from President Trump that "America wasn't built to be shut down", or that "We cannot let the cure be worse than the problem itself", may have influenced citizens from Republican states more than those from Democratic states, which in turn would have resulted in the former being less inclined to socially distance than the latter 20,21,62.

Our study has some limitations. First, we used a cross-sectional time series database and in this context, causal inferences are difficult to make compared to cohort datasets. Second, the Google COVID-19 Community Mobility Reports database provides measures on mobility based on cellular phone signals, which would not capture mobility of people who do not have cell phones or have them turned off. In addition, this "measurement error" could also be correlated with certain states characteristics, their political orientation, the number of COVID deaths, and the stringency of anti-COVID measures. Finally, using the number of COVID deaths (or cases) as a proxy for citizens' risk perception may not have accounted for their level of interest in the pandemic ${ }^{6,43,62}$.

Third, in the current study, we made use of states and days fixed effects to control for any time-invariant state-level and time-varying unit-invariant unmeasured confounders, respectively. However, in this observational study, omitted variable bias might still exist, because some of the unobserved confounders taken into account in our fixed effects model might interact with our variables of interest and modify our outcome. Future studies should investigate how parameter estimates related to political orientation are themselves modified across different types of socio-demographic strata.

Fourth, we acknowledge that our statistical model might be suboptimal. Indeed, at this point, one lacks strong knowledge to properly model longitudinal effects from outcomes (citizens' mobility) at time $\mathrm{t}$ to exposures (anti-COVID measures and COVID-related deaths) at time $t+j$, as well as from exposures at time $t$ to other exposures at time $t+k$. This is 
because there is a high degree of uncertainty in the lags $\mathrm{j}$ and $\mathrm{k}$, which in turn would typically result in some form of simultaneity bias.

Fifth, in our event-studies, while we were careful that each stratum of covariates contained a substantial number of data for each of the three political categories (to avoid data sparsity), one could still argue that our analysis would be biased by the fact that Democratic states presented with a higher strength of anti-COVID interventions and a greater number of COVID deaths than Republican states. However, we found a significant effect of republicanism at low stringency levels and at low levels of COVID deaths, which suggests that our reported estimates are likely not fallacious.

In short, our parameter estimates of interest should be interpreted as representing estimates of adjusted associations rather than causal estimates per se. With these precautions in mind, we found republicanism to be associated with increased mobility when the stringency of anti-COVID measures increased, as well as over time. In contrast, republicanism was associated with decreased mobility when COVID-related deaths increased. These results raise caution on any simplistic over-interpretation of the impact of polarization in US politics on citizens' behaviour, and more particularly towards over-blaming and stigmatizing Republican states. They also suggest that specific measures could be implemented in Republican states to ensure the lowest possible rates of infection. Relying too much on constraining, "high-costs" measures that are tough to be scrupulously respected, such as business, university and school closures, or stay-at-home orders, might not represent an optimal solution in Republican states. Rather, citizens living in Republican states might be more easily persuaded to socially distance by emphasizing COVID risks based on COVID deaths or cases. Tools such as those provided by behavioural economics, e.g. using scare tactics, might better counteract the negative effects of republicanism on adherence to anti-COVID interventions, than increasing their stringency ${ }^{63}$. 


\section{DATA AVAILABILITY}

The datasets generated during and/or analysed during the current study are available from the corresponding author on reasonable request.

\section{REFERENCES}

1. VanDusky-Allen, J. \& Shvetsova, O. How America's partisan divide over pandemic responses played out in the states. The Conversation https://theconversation.com/how-americas-partisan-divide-over-pandemic-responses-pla yed-out-in-the-states-157565 (2021).

2. Deese, K. 70 percent of new coronavirus cases are coming from red states. The Hill https://thehill.com/homenews/state-watch/515038-70-percent-of-new-coronavirus-casesare-coming-from-red-states (2020).

3. Pedersen, M. J. \& Favero, N. Social Distancing during the COVID-19 Pandemic: Who Are the Present and Future Noncompliers? Public Adm. Rev. 80, 805-814 (2020).

4. Leventhal, A. M. et al. Association of Political Party Affiliation With Physical Distancing Among Young Adults During the COVID-19 Pandemic. JAMA Intern. Med. 181, 399-403 (2021).

5. Pew Research Center. Republicans, Democrats Move Even Further Apart in Coronavirus Concerns. Pew Research Center - U.S. Politics \& Policy https://www.pewresearch.org/politics/2020/06/25/republicans-democrats-move-even-furt her-apart-in-coronavirus-concerns/ (2020).

6. Barrios, J. M. \& Hochberg, Y. Risk Perception Through the Lens of Politics in the Time of the COVID-19 Pandemic. https://www.nber.org/papers/w27008 (2020) doi:10.3386/w27008. 
7. Adolph, C., Amano, K., Bang-Jensen, B., Fullman, N. \& Wilkerson, J. Pandemic Politics: Timing State-Level Social Distancing Responses to COVID-19. J. Health Polit. Policy Law 46, 211-233 (2021).

8. Gollwitzer, A. et al. Partisan differences in physical distancing are linked to health outcomes during the COVID-19 pandemic. Nat. Hum. Behav. 4, 1186-1197 (2020).

9. Courtemanche, C., Garuccio, J., Le, A., Pinkston, J. \& Yelowitz, A. Strong Social Distancing Measures In The United States Reduced The COVID-19 Growth Rate. Health Aff. (Millwood) 39, 1237-1246 (2020).

10. Brauner, J. M. et al. Inferring the effectiveness of government interventions against COVID-19. Science 371, (2021).

11. Neelon, B., Mutiso, F., Mueller, N. T., Pearce, J. L. \& Benjamin-Neelon, S. E. Associations Between Governor Political Affiliation and COVID-19 Cases, Deaths, and Testing in the U.S. Am. J. Prev. Med. 61, 115-119 (2021).

12. Prasad, S. \& Hswen, Y. Political Affiliation and Human Mobility Under Stay-at-Home Orders: A Difference-in-Difference Analysis with County and Time Fixed Effects. Harvard Public Health Review: A Peer-Reviewed Journal https://harvardpublichealthreview.org/stay-at-home-orders/ (2020).

13. Berry, C. R., Fowler, A., Glazer, T., Handel-Meyer, S. \& MacMillen, A. Evaluating the effects of shelter-in-place policies during the COVID-19 pandemic. Proc. Natl. Acad. Sci. 118, (2021).

14. Andersen, M. Early Evidence on Social Distancing in Response to COVID-19 in the United States. https://papers.ssrn.com/abstract=3569368 (2020).

15. Brewer, N. T. et al. Meta-analysis of the relationship between risk perception and health behavior: the example of vaccination. Health Psychol. 26, 136 (2007).

16. Rosenstock, I. M. Historical origins of the health belief model. Health Educ. Monogr. 2, 328-335 (1974).

17. Allcott, H. et al. Polarization and public health: Partisan differences in social distancing during the coronavirus pandemic. J. Public Econ. 191, 104254 (2020). 
18. van der Weerd, W., Timmermans, D. R., Beaujean, D. J., Oudhoff, J. \& van Steenbergen, J. E. Monitoring the level of government trust, risk perception and intention of the general public to adopt protective measures during the influenza $A(H 1 N 1)$ pandemic in the Netherlands. BMC Public Health 11, 575 (2011).

19. Petherick, A. et al. A worldwide assessment of changes in adherence to COVID-19 protective behaviours and hypothesized pandemic fatigue. Nat. Hum. Behav. 1-16 (2021) doi:10.1038/s41562-021-01181-x.

20. Grossman, G., Kim, S., Rexer, J. M. \& Thirumurthy, H. Political partisanship influences behavioral responses to governors' recommendations for COVID-19 prevention in the United States. Proc. Natl. Acad. Sci. 117, 24144-24153 (2020).

21. Gollust, S. E., Nagler, R. H. \& Fowler, E. F. The Emergence of COVID-19 in the US: A Public Health and Political Communication Crisis. J. Health Polit. Policy Law 45, 967-981 (2020).

22. Ilin, C. et al. Public mobility data enables COVID-19 forecasting and management at local and global scales. Sci. Rep. 11, 13531 (2021).

23. Google Mobility Reports. COVID-19 Community Mobility Reports. https://www.google.com/covid19/mobility/ (2021).

24. Drake, T. M. et al. The effects of physical distancing on population mobility during the COVID-19 pandemic in the UK. Lancet Digit. Health 2, e385-e387 (2020).

25. Ballotpedia. State government trifectas - Ballotpedia. https://ballotpedia.org/State_government_trifectas (2021).

26. OxCGRT. OxCGRT/covid-policy-tracker. (Oxford Covid-19 Government Response Tracker, 2021).

27. OxCGRT. OxCGRT/USA-covid-policy. GitHub https://github.com/OxCGRT/USA-covid-policy.

28. Zhang, L., Brikell, I., Dalsgaard, S. \& Chang, Z. Public Mobility and Social Media Attention in Response to COVID-19 in Sweden and Denmark. JAMA Netw. Open 4, e2033478 (2021) 
29. Weather Underground. Local Weather Forecast, News and Conditions | Weather Underground. https://www.wunderground.com/.

30. Bargain, O. \& Aminjonov, U. Trust and compliance to public health policies in times of COVID-19. J. Public Econ. 192, 104316 (2020).

31. Chan, H. F. et al. How confidence in health care systems affects mobility and compliance during the COVID-19 pandemic. PLOS ONE 15, e0240644 (2020).

32. Brouard, S., Vasilopoulos, P. \& Becher, M. Sociodemographic and Psychological Correlates of Compliance with the COVID-19 Public Health Measures in France. Can. J. Polit. Sci. Can. Sci. Polit. 53, 253-258 (2020).

33. Jay, J. et al. Neighbourhood income and physical distancing during the COVID-19 pandemic in the United States. Nat. Hum. Behav. 4, 1294-1302 (2020).

34. Nivette, A. et al. Non-compliance with COVID-19-related public health measures among young adults in Switzerland: Insights from a longitudinal cohort study. Soc. Sci. Med. 268, 113370 (2021).

35. Pew Research Center. An examination of the 2016 electorate, based on validated voters. Pew Research Center - U.S. Politics \& Policy https://www.pewresearch.org/politics/2018/08/09/an-examination-of-the-2016-electoratebased-on-validated-voters/ (2018).

36. Lerman, A. E., Sadin, M. L. \& Trachtman, S. Policy Uptake as Political Behavior: Evidence from the Affordable Care Act. Am. Polit. Sci. Rev. 111, 755-770 (2017).

37. Long, E. F., Chen, M. K. \& Rohla, R. Political storms: Emergent partisan skepticism of hurricane risks. Sci. Adv. 6, eabb7906.

38. Suryadevara, M., Bonville, C. A., Cibula, D. A., Domachowske, J. B. \& Suryadevara, A. C. Associations between population based voting trends during the 2016 US presidential election and adolescent vaccination rates. Vaccine 37, 1160-1167 (2019).

39. Druckman, J. N., Peterson, E. \& Slothuus, R. How Elite Partisan Polarization Affects Public Opinion Formation. Am. Polit. Sci. Rev. 107, 57-79 (2013).

40. Gadarian, S. K., Goodman, S. W. \& Pepinsky, T. B. Partisanship, health behavior, and 
policy attitudes in the early stages of the COVID-19 pandemic. PLOS ONE 16, e0249596 (2021).

41. Clinton, J., Cohen, J., Lapinski, J. \& Trussler, M. Partisan pandemic: How partisanship and public health concerns affect individuals' social mobility during COVID-19. Sci. Adv. 7, eabd7204 (2021).

42. Bisbee, J. \& Lee, D. Mobility and Elite Cues: Partisan Responses to Covid-19. (2020) doi:10.33774/apsa-2020-76tv9.

43. Wang, V. H.-C. \& Pagán, J. A. Views on the need to implement restriction policies to be able to address COVID-19 in the United States. Prev. Med. 143, 106388 (2021).

44. Graham, J., Nosek, B. A. \& Haidt, J. The Moral Stereotypes of Liberals and Conservatives: Exaggeration of Differences across the Political Spectrum. PLOS ONE 7, e50092 (2012).

45. Pew Research Center. Public Opinion on Patriotism, Personal Traits, Lifestyles and Demographics. Pew Research Center - U.S. Politics \& Policy https://www.pewresearch.org/politics/2014/06/26/section-9-patriotism-personal-traits-lifes tyles-and-demographics/ (2014).

46. Preston, O. C. \& Anestis, J. C. Psychopathic traits and politics: Examining affiliation, support of political issues, and the role of empathy. Personal. Individ. Differ. 131, 142-148 (2018).

47. Arvan, M. "A Lot More Bad News for Conservatives, and a Little Bit of Bad News for Liberals? Moral Judgments and the Dark Triad Personality Traits: A Follow-up Study". Neuroethics 6, 51-64 (2013).

48. Lilienfeld, S. O., Latzman, R. D., Watts, A. L., Smith, S. F. \& Dutton, K. Correlates of psychopathic personality traits in everyday life: results from a large community survey. Front. Psychol. 5, 740 (2014).

49. Alfano, V. \& Ercolano, S. Stay at Home! Governance Quality and Effectiveness of Lockdown. Soc. Indic. Res. (2021) doi:10.1007/s11205-021-02742-3.

50. Levi, M. \& Stoker, L. Political Trust and Trustworthiness. Annu. Rev. Polit. Sci. 3, 
475-507 (2000).

51. Eriksson, K. Republicans Value Agency, Democrats Value Communion. Soc. Psychol. Q. 81, 173-184 (2018).

52. Pew Research Center. Appendix 1: Typology Group Profiles. Pew Research Center U.S. Politics \& Policy https://www.pewresearch.org/politics/2014/06/26/appendix-1-typology-group-profiles/ (2014).

53. Leone, L. \& Chirumbolo, A. Conservatism as motivated avoidance of affect: Need for affect scales predict conservatism measures. J. Res. Personal. 42, 755-762 (2008).

54. Inbar, Y. \& Pizarro, D. A. Pathogens and politics: current research and new questions. Soc. Personal. Psychol. Compass 10, 365-374 (2016).

55. Oosterhoff, B., Shook, N. J. \& Ford, C. Is that disgust I see? Political ideology and biased visual attention. Behav. Brain Res. 336, 227-235 (2018).

56. Povich, E. S. GOP Governors Reject Extra Federal Unemployment Payments. The Pew Charitable Trusts https://pew.org/2SHoZ00 (2021).

57. Santana, F. N., Fischer, S. L., Jaeger, M. O. \& Wong-Parodi, G. Responding to simultaneous crises: Communications and social norms of mask behavior during wildfires and COVID-19. Env. Res Lett 15, 111002 (2020).

58. Christensen, S. R. et al. Political and personal reactions to COVID-19 during initial weeks of social distancing in the United States. PLOS ONE 15, e0239693 (2020).

59. Michie, S., West, R. \& Harvey, N. The concept of "fatigue" in tackling covid-19. bmj 371, (2020).

60. World Health Organization. Regional Office for Europe. Pandemic fatigue: reinvigorating the public to prevent COVID-19: policy framework for supporting pandemic prevention and management: revised version November 2020. https://apps.who.int/iris/handle/10665/337574 (2020).

61. Lopez, G. How pandemic fatigue and polarization led to Wisconsin's massive Covid-19 outbreak. Vox 
https://www.vox.com/future-perfect/21523259/wisconsin-covid-coronavirus-cases-tony-e vers-trump-democrats-republicans (2020).

62. Jiang, J., Chen, E., Yan, S., Lerman, K. \& Ferrara, E. Political polarization drives online conversations about COVID-19 in the United States. Hum. Behav. Emerg. Technol. 2, 200-211 (2020).

63. Lunn, P. D. et al. Using Behavioral Science to help fight the Coronavirus. J. Behav. Public Adm. 3, (2020).

\section{AUTHOR CONTRIBUTIONS}

GB has conceived the study and extracted the data.

GB and NF have analysed and interpreted the data, drafted the paper and revised it. Both authors have approved the submitted version and have agreed to be personally accountable for the accuracy and integrity of any part of the work.

All methods were carried out in accordance with relevant guidelines and regulations.

\section{COMPETING INTERESTS}

The authors declare no competing interests. 


\section{FIGURES AND TABLES}

Figure 1. US citizens' mobility to transit stations for each political group during the first period of the pandemic (Feb 15 to May 31 2020)

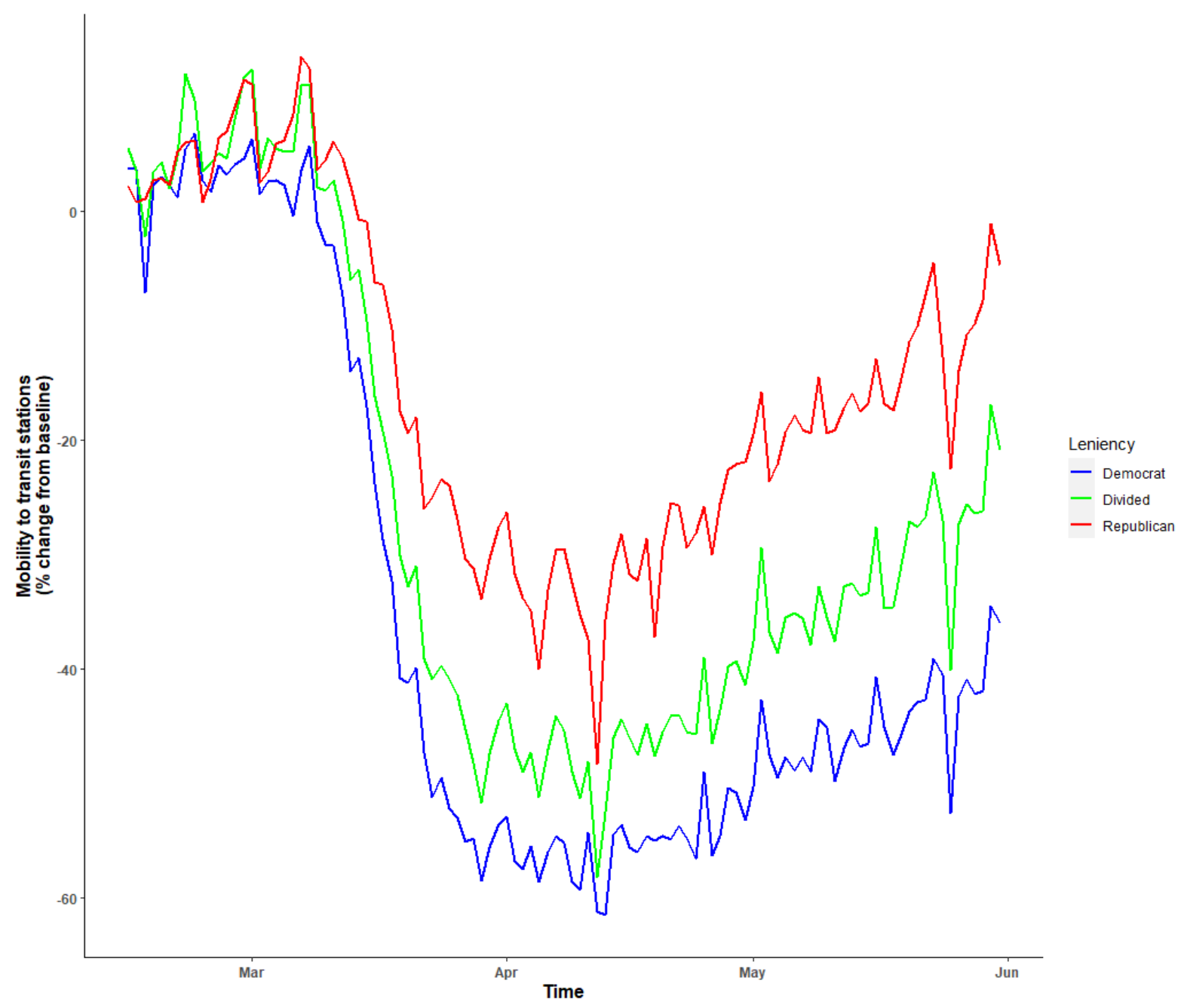

Mean daily percentage signal change from baseline is plotted as a function of time for each political group. See main text for a definition of the baseline period. 
Figure 2. Stringency of anti-COVID measures (A) and Number of COVID-related deaths (B) for each political group during the first period of the pandemic (Feb 15 to May 31 2020)

A

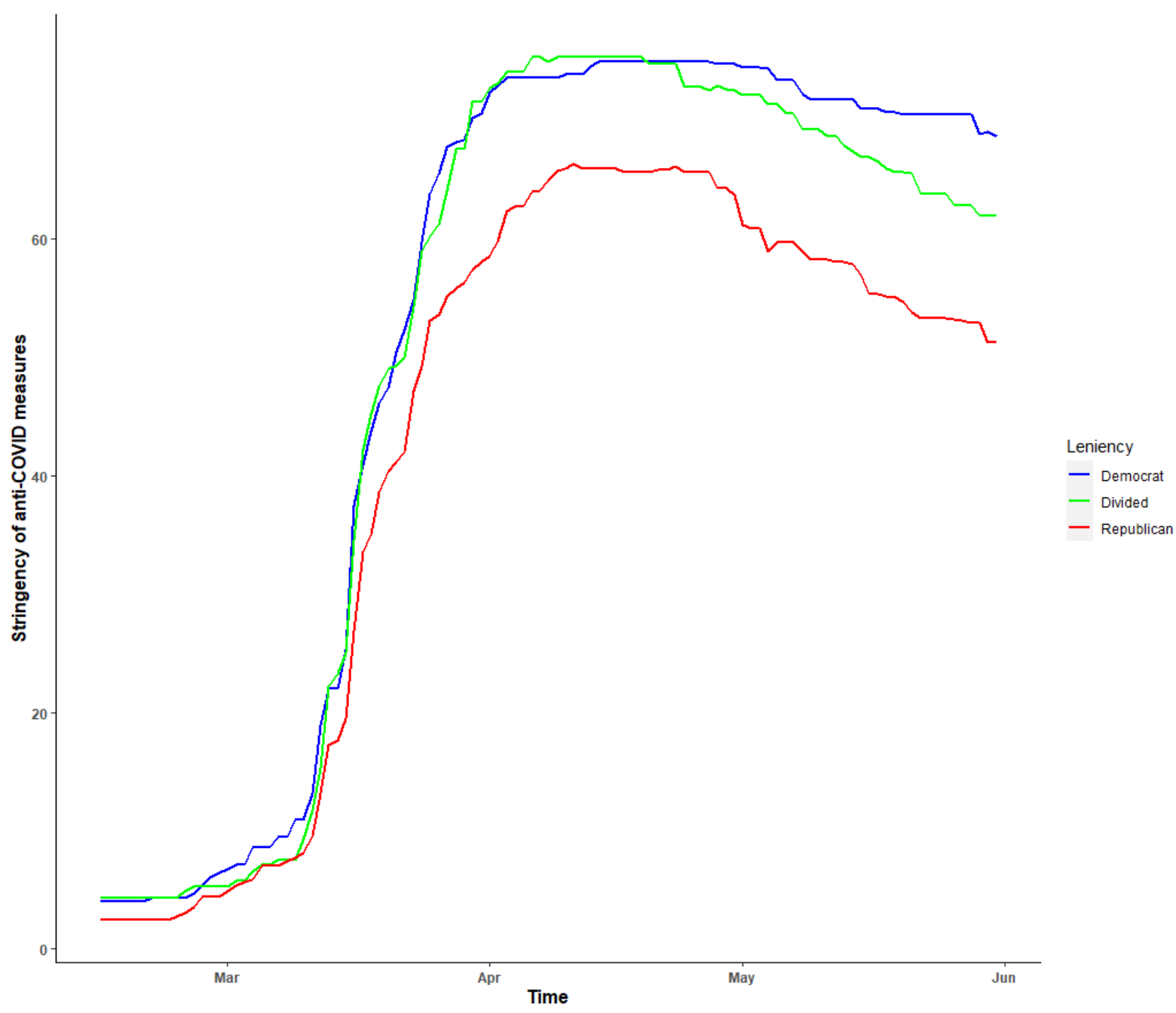

Mean stringency level of anti-COVID measures is plotted as a function of time for each political group. 
B

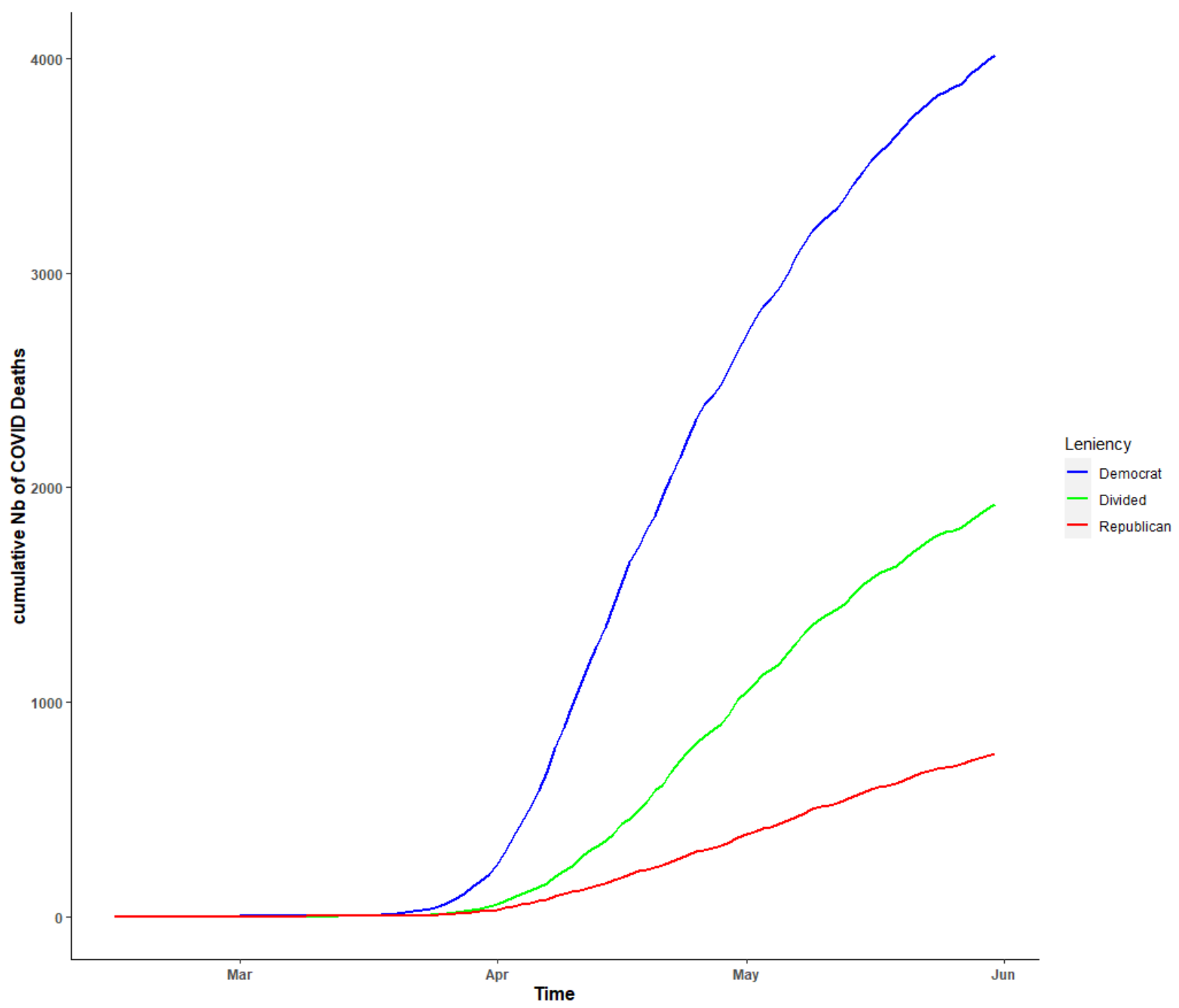

Mean cumulative number of COVID-related deaths is plotted as a function of time for each political group. 
Table 1. Parameter estimates, standard errors (SE) and $p$ values from our main model (with mobility to transit stations as the dependent variable)

\begin{tabular}{|l|l|l|l|}
\hline & \multicolumn{4}{|l|}{ Mobility to transit stations } \\
\hline Variable & Estimate & SE & p value \\
\hline Stringency & -0.2126 & 0.0673 & $\mathbf{0 . 0 0 2 7}$ \\
\hline COVID Deaths & -0.0003 & 0.0001 & $\mathbf{0 . 0 0 7 3}$ \\
\hline Temp & 0.4187 & 0.2060 & $\mathbf{0 . 0 4 7 5}$ \\
\hline Temp^2 & -0.0027 & 0.0020 & 0.1952 \\
\hline $\begin{array}{l}\text { Stringency } \mathbf{x} \\
\text { Republicanism }\end{array}$ & 0.0810 & 0.0282 & $\mathbf{0 . 0 0 6 0}$ \\
\hline $\begin{array}{l}\text { COVID Deaths } \mathbf{x} \\
\text { Republicanism }\end{array}$ & -0.0031 & 0.0007 & $\mathbf{0 . 0 0 0 0}$ \\
\hline $\begin{array}{l}\text { Temporal Linear trend } \mathbf{x} \\
\text { Republicanism }\end{array}$ & 0.1076 & 0.0201 & $\mathbf{0 . 0 0 0 0}$ \\
\hline
\end{tabular}


Figure 3. Event-study plots representing the effect of stringency of anti-COVID measures, number of COVID deaths and time on mobility to transit stations, modified by republicanism
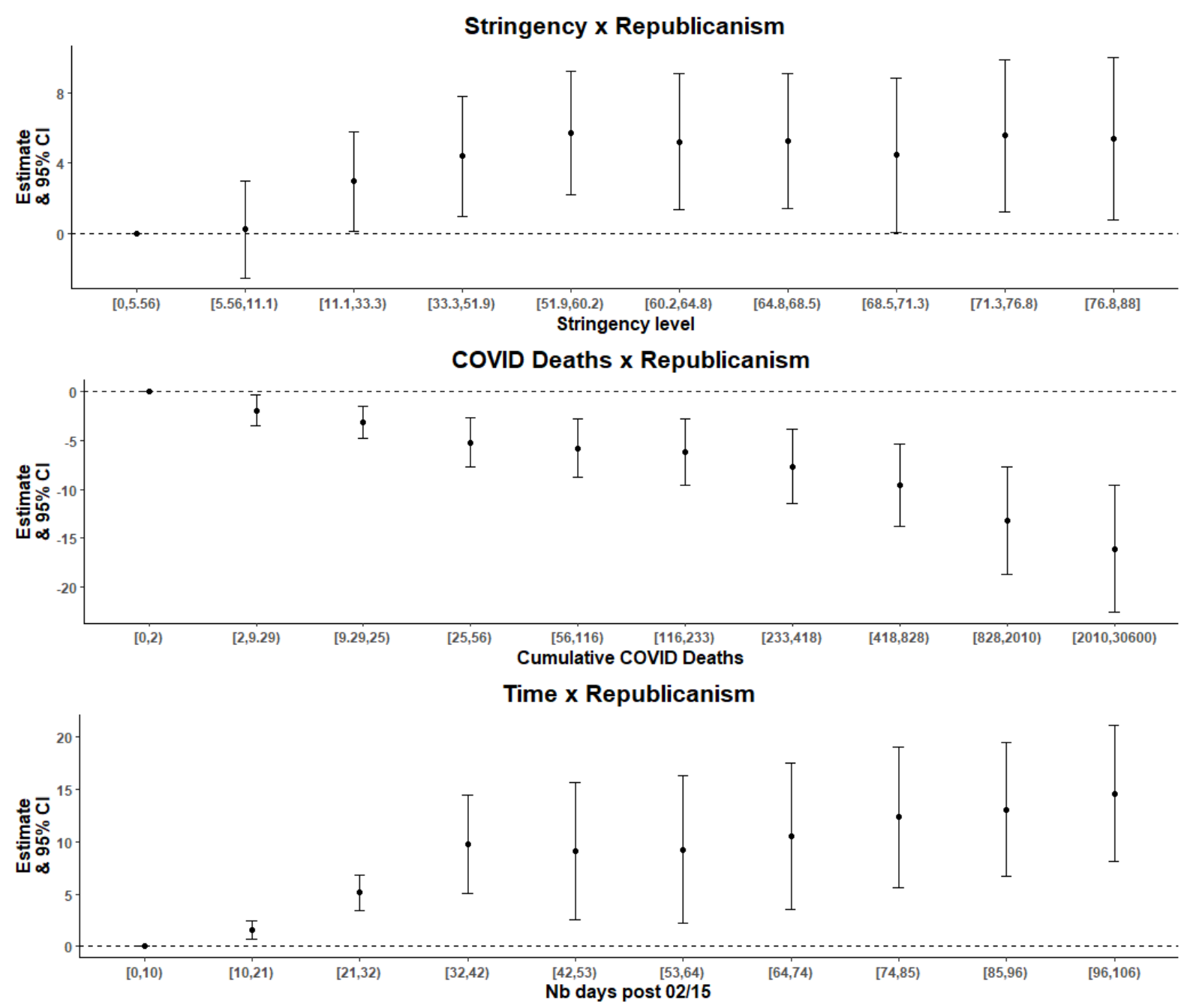

In each panel, the reference represents the effect of republicanism on mobility at the lowest value of the variable represented on the $x$ axis (i.e. the lowest stringency level, the lowest number of COVID-related deaths, and the lowest number of days after Feb. 152020 - the beginning of the time series). At the reference point, the value of the corresponding parameter estimate is of 0 . Other estimates have to be interpreted relative to the reference point. For instance, compared to the reference point, increasing the stringency of anti-COVID measures is associated with an increased effect of republicanism on mobility to transit stations. 


\section{Supplementary Files}

This is a list of supplementary files associated with this preprint. Click to download.

- MobilityandRepublicanismCOVIDSOM.pdf 